\title{
THE INFLUENCE OF NEIGHBOURING GRASSES ON THE GROWTH OF WHITE CLOVER (TRIFOLIUM REPENS L.)
}

\author{
S.M. SOLANGAARACHCHI* \\ Unit of Plant Population Biology, School of Biological Sciences, University \\ College of North Wales, Bangor, Gwynedd, LL57 2UW, U.K.
}

(Received: O1June 1995; accepted: 12 January 1996)

\begin{abstract}
Plants of white clover (Trifolium repens) were allowed to grow across a boundary between bare ground and a grass sward of Lolium perenne, Cynosurus cristatus, Holcus lanatus or Agrostis tenuis which was defoliated to $4 \mathrm{~cm}$ height at ten day intervals. Growth of the clover was strongly suppressed within the grass canopies. Canopies of H. lanatus and A. tenuis produced the greatestreduction in photosynthetically active radiation beneath them and most reduced the growth of $T$. repens. The canopy of $H$. lanatus reduced the ratio of red to far red radiation more than the canopy of the other grass species. Clones of clover differed in their response to the grass species. Clover was allowed to grow into swards of $L$. perenne that had been repeatedly defoliated to different heights. Clover invasion was reduced by increasing height of the sward and branching was largely inhibited in the taller swards. In the shortest swards the plants branched as freely as in bare ground.
\end{abstract}

Key words: Grasses, Trifolium repens, white clover.

\section{INTRODUCTION}

Mixed communities of grasses and clovers (especially Trifolium repens L.) form the greater part of the grazed plant communities in northern and southern temperate countries. The grasses provide the bulk of the fodder for the grazing animal but the legume is important because it enriches the protein content of the fodder due to its association with nitrogen fixing Rhizobium. The relative proportions of grasses and clovers in a pasture become important because if clover becomes dominant the productivity of the pasture falls and if the grass becomes dominant the nutritive value of the herbage declines.

Until recently the studies on grass - clover balance have taken a holistic view of the sward and measured the gross changes in yield and species composition of whole pastures or experimental plots that result from different management practices. The degree of grass dominance can be increased by allowing the sward to grow tall or by applying nitrogen fertilizers. The contribution of clover to the sward can usually be increased by maintaining the sward short. The timing of defoliation can also have a significant effect on the grass - clover balance because the main flush of clover growth follows that of most of the pasture grasses; hence

\footnotetext{
* Present address: Department of Botany, University of Kelaniya, Kelaniya, Sri Lanka.
} 
defoliation when the grasses are growing fast may leave the sward more open for the later growth of clover.$^{1-5}$ Recent work at the community level has largely expanded this knowledge.

The holistic studies give predictive information that has rapidly been incorporated into management practice but do not focus on the processes of birth and death of individual plants and their parts that underlie the gross processes of invasion and retreat that cause changes in pasture composition. In particular holistic studies usually treat the grassland community as if it is homogeneous. However Leith ${ }^{6}$ showed that not only was a grassland community commonly a mosaic of small patches dominated by different species but also that the mosaic could change dramatically within a year so that very local patches dominated by clover in one year were grass dominated in the following year while previously grass dominated patches had become occupied by clover. This picture of grassland as a continually changing mosaic of patches occupied by different species focusses attention on the ways in which individual plants invade and recede from patches dominated by each other. The overall balance of species within the sward must be the result of changes in local distributions, not just changes in proportions.

Most common grasses in temperate grasslands, e.g. Lolium perenne, Dactylis glomerata, Holcus lanatus, Agrostis tenuis, and Phleum pratense, cannot spread extensively by rhizomes or stolons and they form tiller clusters. They have 'phalangeal' growth form in which much of the competition for resources must be concentrated between tillers and roots of the same plant. In contrast, plants of $T$. repens has a 'guerilla' growth form of laterally extending plagiotropic stems (stolons) which continually grow forward in the sward, with or without branching forced by their morphology continually to migrate or wander within the grassland mosaic.

The image of grassland as a mosaic of species some of which are continually migrating by vegetative growth while others occupy their local sites from establishment until death, immediately focusses attention on what happens at the interfaces between individual plants. Traditional experimental designs deliberately exclude edge effects but the explanation of species interactions may lie in studying edges and interfaces.

A previous paper describes the response of clover plants to other clover plants in the neighbourhood. ${ }^{7}$ In the present paper the behaviour of clover plants when they grow into patches dominated by grasses is described. It compares clover growth into different species of grass and into grass that has been defoliated to different heights. 


\section{METHODS AND MATERIALS}

Comparison of the invasiveness of clones of T. repens into swards of grasses: Populations of four grass species $L$. perenne, H. lanatus, C. cristatus and A. tenuis were grown from seed in wooden boxes $(40 \times 30 \times 9 \mathrm{~cm})$ filled with John Innes Compost No 1 . The seeds were sown and the populations were allowed to develop in an unheated glasshouse. The swards were then removed from their boxes and placed on soil beds of John Innes Compost No 1 . A $22 \mathrm{~cm}$ wide border along the edges of the grass swards was filled with the same compost to the same level as. that of the swards. Each experimental plot was separated from its neighbours by wooden boards extending just above the soil surface. Control plots contained no grass.

Two clones of $T$. repens were selected from a collection made by Trathan ${ }^{8}$ from a permanent pasture in North Wales. These were chosen to represent differences in growth form and were two of the same clones that had been used in an earlier study. ${ }^{7}$ Clone A had short internodes, short petioles, relatively small leaves and thin stolons; clone $\mathrm{B}$ had longer internodes and petioles, more vertically held petioles and thicker stolons. Plants were grown from single node cuttings and selected for uniformity when one month old. Four clover plants of the same clone were transplanted into the compost at equal distances $(6 \mathrm{~cm})$ apart along the edge of each of the grass swards with the main stolon tips pointing towards the swards.

The experiment involved four grass species + control $\mathrm{x} 2$ clover clones $\mathrm{x} 3$ replicates arranged in a randomised block design. The swards were watered regularly and clipped to $4 \mathrm{~cm}$ height at 7 - 10 day intervals. Only the main stolon from each clover plant and its primary branches were allowed to grow into the sward. Any other branches that formed outside the grass canopy were redirected to prevent them entering the sward. After 11 weeks the clover plants were harvested and measurements were made of (a) the number of nodes, (b) the length of stolons, (c) the dry weight of stolons of each order of branching and (d) the number of branched nodes. The dry weight of the above ground parts of the grasses and the density of tillers were also determined. Before harvest the intensity of Photosynthetically Active Radiation(PAR) and the ratio of red to far red radiation $(\zeta)$ beneath each type of sward were measured using a Multisensor. ${ }^{9}$ Holes were made from underneath the soil bed with minimal disturbance to the grass canopy so that the sensor head was beneath the sward and level with the soil surface.

The effect of defoliation of the grasses on invasion of swards by T. repens : Two week old seedlings of $L$. perenne (Aberyswyth Strain S23) were planted in trays

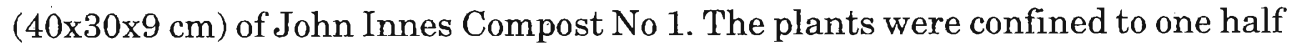
of each tray in which their density was equivalent to $6250 \mathrm{~m}^{-2}$. The remaining 
half of each tray was left free of grass. Single node cuttings of clover were rooted in John Innes Compost No 2, selected for uniformity and transplanted into the grass-free area of each tray. Control trays contained no grass. Four clover plants were inserted into each tray at a distance of $10 \mathrm{~cm}$ from, and with the main stolon tips pointing towards, the grass. In the controls, the clover plants were introduced into the same positions as if the grass had been present. The grasses were clipped to 9,6 or $3 \mathrm{~cm}$ height (after four weeks of growth) at 7 day intervals but the clover leaves were left uncut. Each treatment was replicated three times in a completely randomised design and the position of trays was rerandomised weekly.

Ten weeks after the start of the experiment leaves of clover from each of the trays were sampled and the length of the petioles and of the middle leaflet were measured. All the leaves of both grasses and clover were then removed and maps of the distribution of the stolons were prepared. Transects of contiguous quadrats, $2 \mathrm{~cm}$ long and $7 \mathrm{~cm}$ wide were drawn (which covered the length of the whole tray) across the maps at right angles to the grass clover interface and the number of nodes, length of stolons, number of branched stolons and mean internode length were determined in each quadrat.

\section{RESULTS}

Invasiveness of clover into swards of grass species : The growth of clover plants into the grass swards was greatly reduced, compared with that made into the control (bare) areas (Table 1). The total number of nodes formed was reduced to $15 \%$ of the controls in swards of C. cristatus and to $13 \%$ in swards of $L$. perenne. The reduction was even greater in swards of $A$. tenuis $(8 \%)$ and $H$. lanatus $(7 \%)$. The total number of nodes formed is the sum of those developed on the main axis and on primary, secondary and higher order branches. The number of nodes produced by the main stolon was reduced in the L.perenne swards to $79 \%$ and in the swards of the other three grasses to $64 \%$ of the controls. However the main effect of growth into the grass canopies was a reduction in the number of branches. The number of nodes on primary branches of clover was reduced to $22 \%$ of the controls in swards of L. perenne, $21 \%$ in C. cristatus and significantly even more reduced to $13 \%$ of the controls in the A. tenuis and $11 \%$ in the $H$. lanatus swards.

The growth of clover into a grass sward may be measured by the increase in length of the main stolon (a measure of the distance of penetration) and by the weight of the whole shoot within the sward (a measure of exploitation that mainly reflects the growth made by lateral branches from the main stolon). The weight of the shoot divided by the length of the main stolon gives a measure of the behaviour of an invading clover stolon. In the control plots, $0.21 \mathrm{~g}$ of shoot were produced per centimetre of main stolon but in the grass plots the values 
varied between 0.02 and $0.04 \mathrm{~g} \mathrm{~cm}^{-1}$, i.e. the clover plants in the grass swards extended their main stolons far into the sward compared with the total growth that they made.

Table 1: The effect of different grass species, Lolium perenne (L p), Cynosurus cristatus (C c), Holcus lanatus (H 1$)$ and Agrostis tenuis (A t) on the performance of Trifolium repens.

\begin{tabular}{|c|c|c|c|c|c|}
\hline \multirow{2}{*}{ Variable } & \multicolumn{5}{|c|}{ Treatments } \\
\hline & Control & $\mathrm{L} \mathrm{p}$ & $\mathrm{C} \mathrm{c}$ & $\mathrm{H} \mathrm{l}$ & At \\
\hline \multicolumn{6}{|l|}{ Number of nodes } \\
\hline Main stolon ${ }^{*}$ & $36.2^{\mathrm{a}}$ & $28.5^{\mathrm{b}}$ & $23.5^{\mathrm{c}}$ & $23.7^{\mathrm{c}}$ & $21.8^{\mathrm{c}}$ \\
\hline Primary stolon* & $508.3^{a}$ & $113.3^{b}$ & $108.5^{b}$ & $56.4^{c}$ & $68.2^{c}$ \\
\hline Secondary stolon* & $1046.1^{\mathrm{a}}$ & $79.1^{\text {bd }}$ & $104.6^{b}$ & $41.6^{c}$ & $50.6^{\mathrm{cd}}$ \\
\hline Total & $1773.0^{\mathrm{a}}$ & $235.0^{\mathrm{bc}}$ & $265.0^{\mathrm{b}}$ & $125.0^{\text {de }}$ & $150.0^{\text {ce }}$ \\
\hline \multicolumn{6}{|l|}{ Length $(\mathrm{cm})$ : } \\
\hline Main stolon & $61.6^{\mathrm{a}}$ & $41.9^{b}$ & $31.5^{\mathrm{c}}$ & $26.6^{\mathrm{c}}$ & $26.7^{\mathrm{c}}$ \\
\hline Primary stolon & $615.8^{\mathrm{a}}$ & $124.4^{\mathrm{b}}$ & $116.3^{b}$ & $53.8^{c}$ & $71.1^{c}$ \\
\hline Secondary stolon & $745.0^{\mathrm{a}}$ & $72.0^{\text {be }}$ & $101.0^{c}$ & $32.0^{d}$ & $51.0^{\text {de }}$ \\
\hline Total & $1507.0^{\mathrm{a}}$ & $250.0^{\mathrm{b}}$ & $275.0^{\mathrm{b}}$ & $114.0^{\mathrm{b}}$ & $158.0^{\mathrm{b}}$ \\
\hline
\end{tabular}

Dry weight (g):

Main stolon

Primary stolon

$0.281^{\mathrm{a}}$

$0.102^{\mathrm{b}}$

$0.078^{\mathrm{bc}}$

$0.068^{\mathrm{c}}$

$0.078^{b}$

Secondary stolon

$2.675^{\mathrm{a}}$

$0.198^{\mathrm{b}}$

$0.252^{\mathrm{b}}$

$0.136^{\mathrm{b}}$

$0.158^{\mathrm{b}}$

Total

$3.363^{\mathrm{a}}$

$0.131^{\mathrm{b}}$

$0.171^{\mathrm{b}}$

$0.060^{\mathrm{b}}$

$0.095^{b}$

$6.564^{\mathrm{a}}$

$0.437^{\mathrm{b}}$

$0.549^{b}$

$0.265^{b}$

$0.341^{b}$

Number of branched nodes*

$479.9^{a}$

$52.9^{\mathrm{b}}$

$64.9^{\mathrm{b}}$

$8.5^{\mathrm{c}}$

$36.0^{c}$

Dry weight of shoot (g)

$13.32^{a}$

$1.22^{\mathrm{b}}$

$1.37^{\mathrm{b}}$

$0.64^{\mathrm{b}}$

$0.81^{\mathrm{b}}$

'Invasiveness'

$0.218^{a}$

$0.029^{b}$

$0.048^{\mathrm{b}}$

$0.0241^{b}$

$0.029^{b}$

* Analysis of variance was carried out on Log transformed data in order to increase the homogeneity of variance.

Each value represents an overall mean of 24 replicates ( 4 replicate plants, 3 replicate grass blocks, 2 clones) of both clones. Means were compared with the Tukey's HSD value. Means sharing the same superscript within each row do not differ significantly $(\mathrm{p}>0.05)$. 
When the mean values of all treatments were compared, the two clones were found to differ significantly in several respects (Table 2). Clone B developed 16\% more nodes, $48 \%$ greater length of stolons, $164 \%$ greater weight of stolons and $129 \%$ greater total shoot weight. The response of the two clones to treatments are summarised in Fig. 1a-d. Clone B was less suppressed by the grassses than Clone A, but Clone B reacted differently to the grass species, being significantly more suppressed by Agrostis and Holcus than by Lolium and Cynosurus.

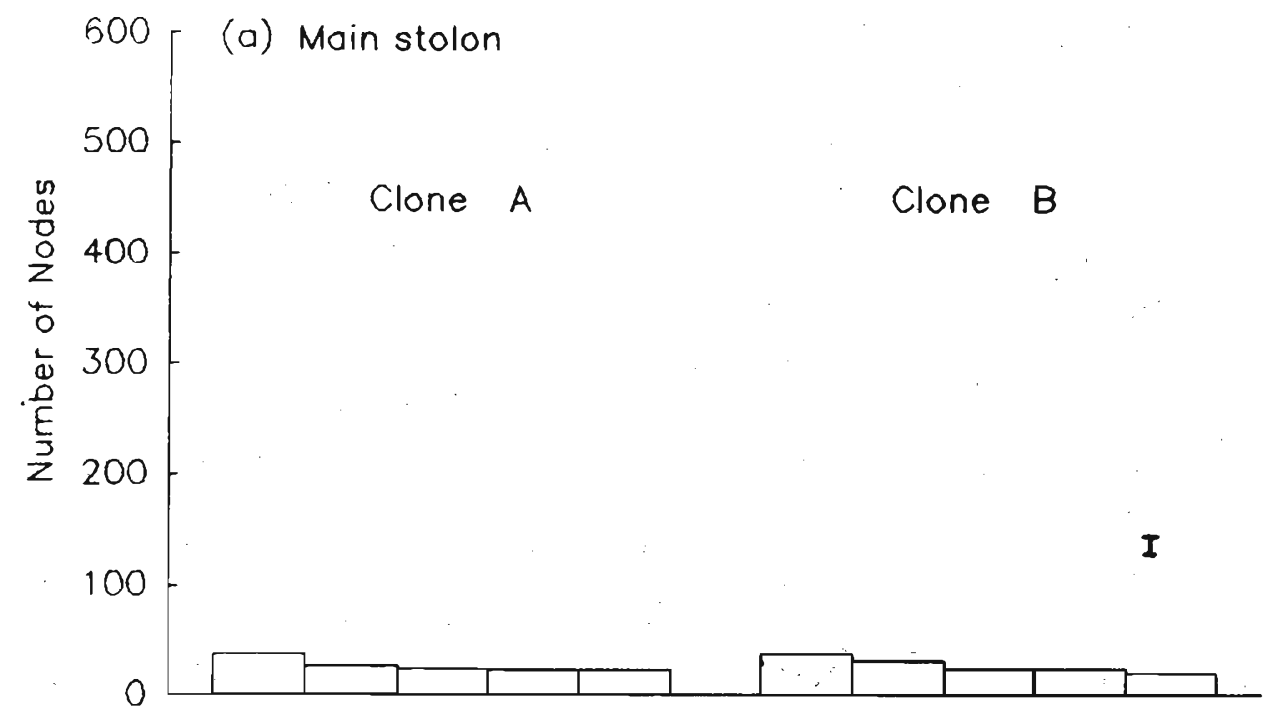

Figure 1a

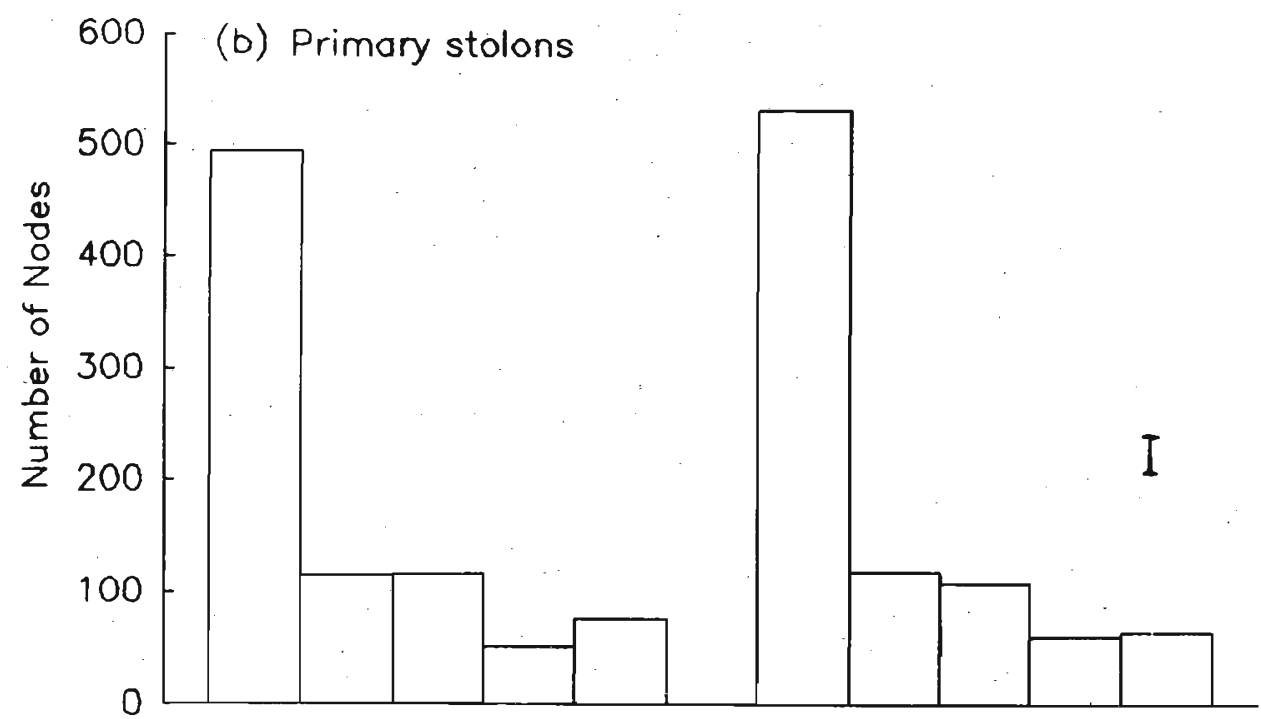

Figure 1 b 


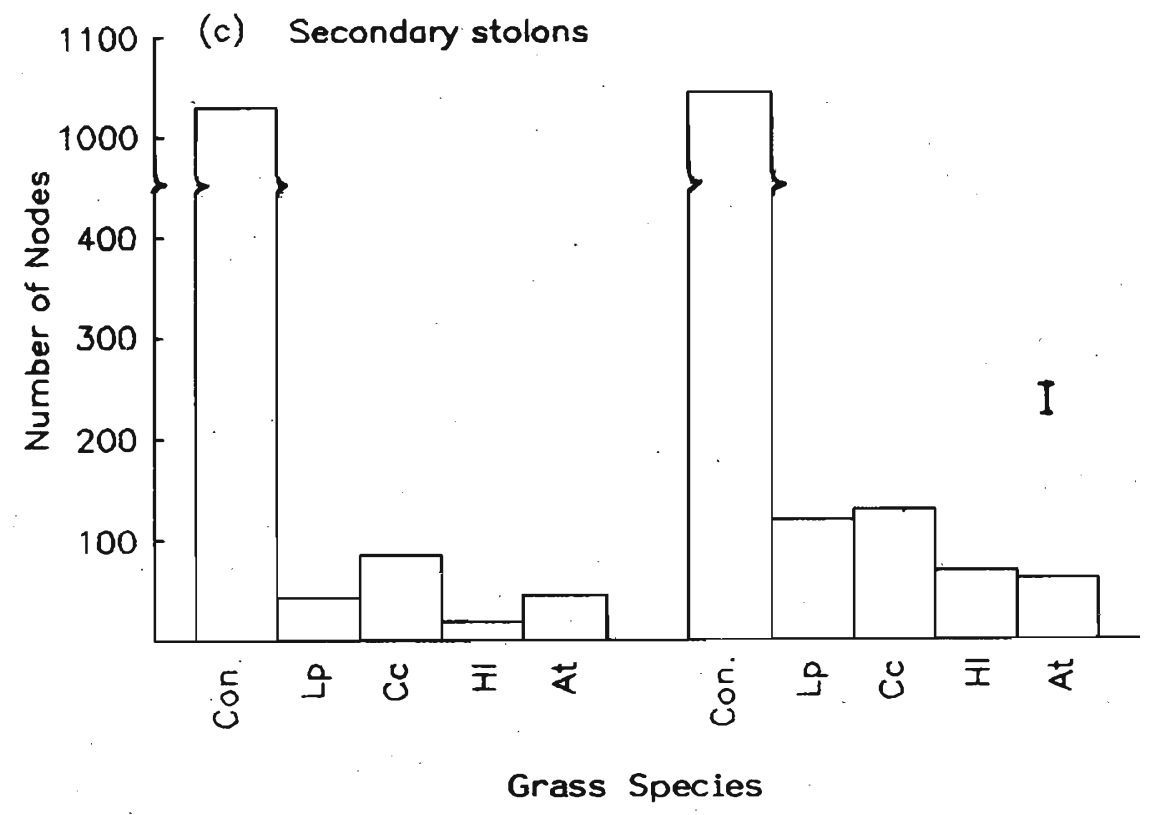

Figure 1c

(d)

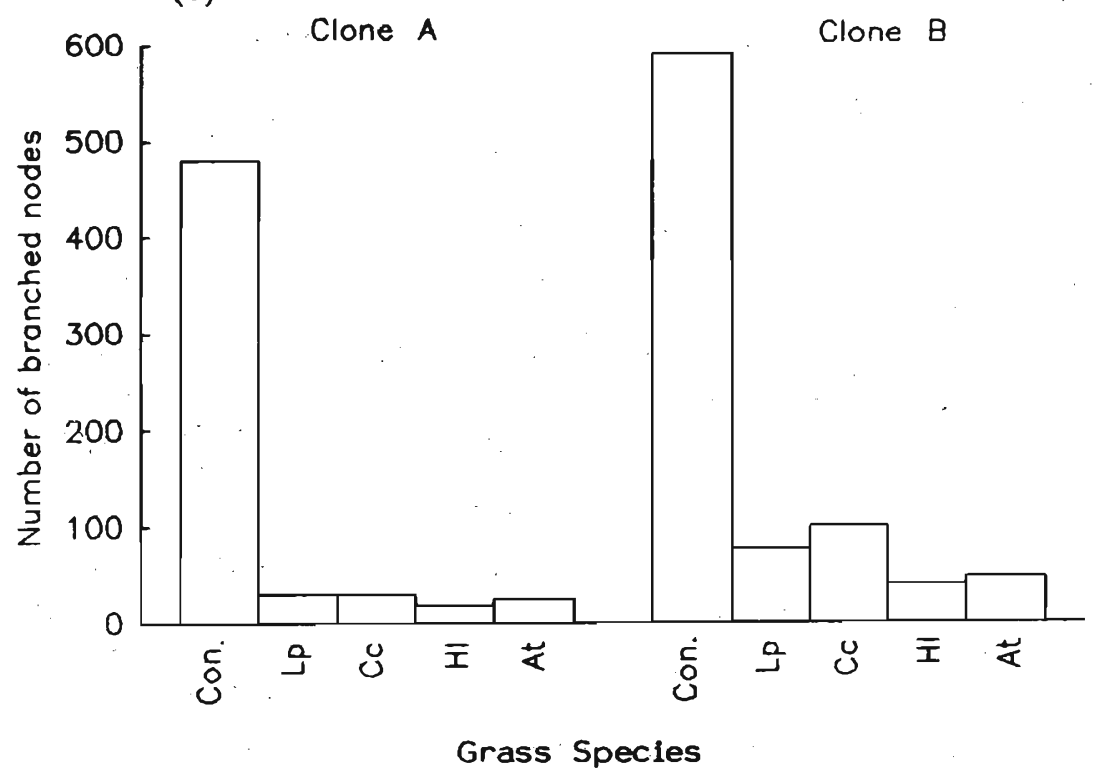

Figure 1d

Figure 1a-d: Comparison of the growth (Number of nodes) of clones (A and B) of Trifolium repens, grown into bare soil (Con), and swards of Lolium perenne (Lp), Cynosurus cristatus (Cc), Holcus lanatus (HI) and Agrostis tenuis (At). (a) Main stolon, (b) Primary stolons, (c) Secondary stolons, (d) Number of branched nodes per plant. In $\dot{a}, \mathrm{~b} \& \mathrm{c}$ vertical bars on the right hand top corner are Tukey's HSD $(p<0.05)$, by which the differences between treatments or clones can be compared. 
Table 2: Comparison of the growth of clones of Trifolium repens (A and B).

\begin{tabular}{|c|c|c|}
\hline \multirow[b]{2}{*}{ Variable } & \multicolumn{2}{|c|}{ Clones } \\
\hline & A & B \\
\hline \multicolumn{3}{|l|}{ Number of nodes } \\
\hline Main stolon* & $27.0^{\mathrm{a}}$ & $26.5^{\mathrm{a}}$ \\
\hline Primary stolon ${ }^{*}$ & $169.1^{\mathrm{a}}$ & $172.8^{\mathrm{a}}$ \\
\hline Secondary stolon* & $245.8^{a}$ & $283.1^{\mathrm{b}}$ \\
\hline Total $^{*}$ & $464.0^{\mathrm{a}}$ & $539.0^{\mathrm{b}}$ \\
\hline \multicolumn{3}{|l|}{ Length $(\mathrm{cm})$ : } \\
\hline Main stolon & $35.3^{a}$ & $40.0^{\mathrm{b}}$ \\
\hline Primary stolon & $167.8^{\mathrm{a}}$ & $224.8^{\mathrm{b}}$ \\
\hline Secondary stolon & $159.0^{\mathrm{a}}$ & $242.0^{\mathrm{a}}$ \\
\hline Total & $370.0^{\mathrm{a}}$ & $551.0^{\mathrm{b}}$ \\
\hline \multicolumn{3}{|l|}{ Dry weight (g): } \\
\hline Main stolon & $0.0747^{\mathrm{a}}$ & $0.1678^{\mathrm{b}}$ \\
\hline Primary stolon & $0.3800^{\mathrm{a}}$ & $0.9880^{\mathrm{b}}$ \\
\hline Secondary stolon & $0.4210^{\mathrm{a}}$ & $1.1080^{\mathrm{b}}$ \\
\hline Total & $0.8940^{\mathrm{a}}$ & $2.3690^{\mathrm{b}}$ \\
\hline Number of branched nodes ${ }^{*}$ & $94.9^{a}$ & $170.1^{b}$ \\
\hline Dry weight of shoot (g) & $2.11^{\mathrm{a}}$ & $4.84^{\mathrm{b}}$ \\
\hline 'Invasiveness' & $0.0423^{a}$ & $0.0970^{b}$ \\
\hline
\end{tabular}

"Analysis of variance was carried out on Log transformed data, in order to increase the homogeneity of variance.

Values are overall means. of all treatments. Means were compared with Tukey's HSD values, and means sharing the same superscript within each row do not differ significantly $(p>0.05)$.

The structure of the Agrostis sward was conspicuously different from that formed by the other species: its tillers were smaller and more densely packed (Fig. 2), producing a more closely knit sward. Holcus accumulated a greater mat of litter than the other species. However there was no significant difference in the dry weight of above ground parts produced by the four species. At the time of harvest, when radiation measurements were made, the swards of Holcus and Agrostis intercepted a significantly greater proportion of PAR than those of Lolium and Cynosurus (Fig. 3a). The ratio of red to far red radiation $(\zeta)$ beneath the swards was significantly lower under Holcus than under the other swards (Fig. 3b). 


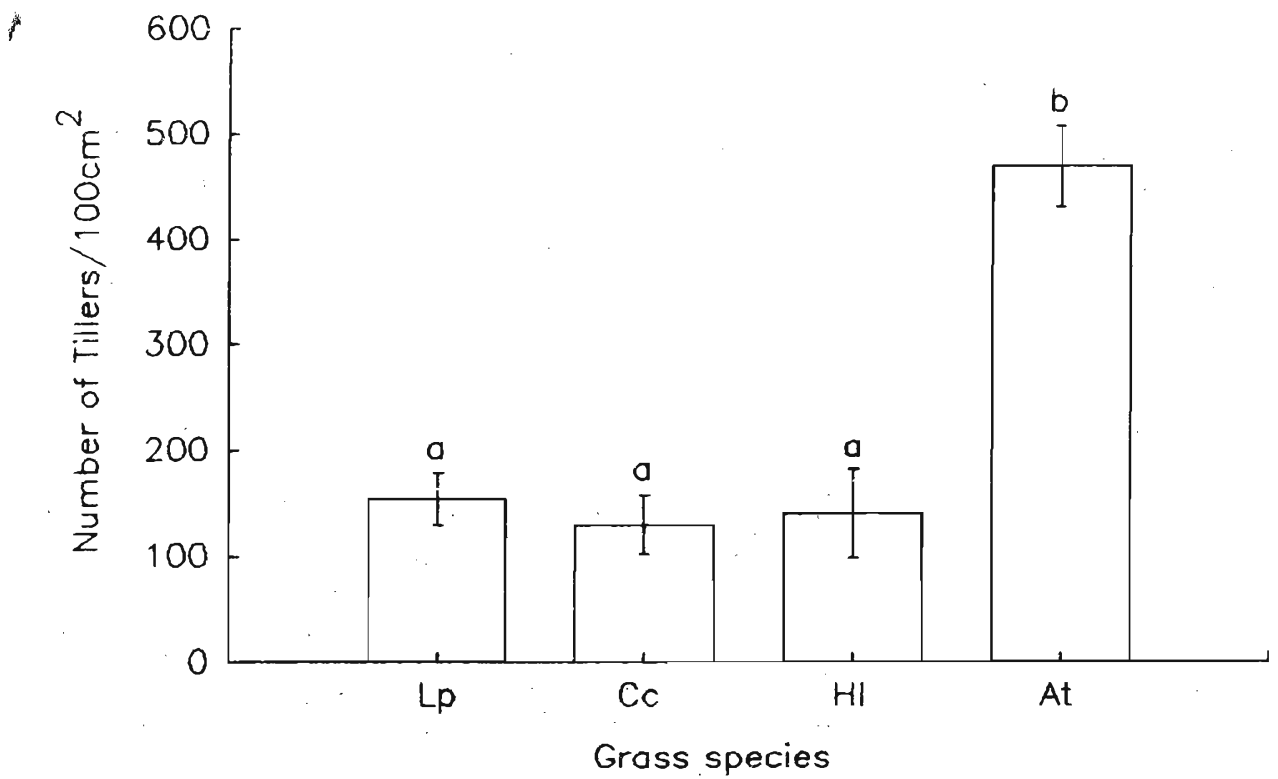

Figure 2: Comparison of the number of tillers per $100 \mathrm{~cm}^{2}$, in the swards of Lolium perenne (Lp), Cynosurus cristatus (Cc), Holcus lanatus (H) and Agrostis tenuis (At), within which Trifolium repens was grown. Each value \pm SE is a mean of 6 replicates. Bars sharing the same letter do not differ significantly $(\mathbf{p}<0.05)$.

Invasion by clover into defoliated grass swards : The effects of defoliated grass swards on the growth of clover are summarised in Table 3 which compares the growth of clover invading the grass swards with that in comparable regions of the control trays which contain no grass. The density of clover nodes was sharply reduced to $48 \%$ of the control in the $3 \mathrm{~cm}$ grass sward and still further with increasing height of the sward. Fewer branched nodes were produced by clover in the grass swards than in the controls and there was also a decline, with height of the sward, in the proportion of nodes that produced branches.

A comparison can also be made between the growth of clover plants on the side of each tray planted with grass and the growth on the unplanted side. The results of this comparison are shown in Table 4 and the changes in number of nodes, branched nodes and in length of stolons are illustrated in Fig. 4a,b and c. The presence of grass on one side of a tray reduced both node density and stolon length of the clover on the unplanted side. The effect was strongest near the grass boundary and this may reflect competition between clover roots and those of the grasses which extend beyond their canopy. The effect was similar for all canopy heights and is therefore unlikely to have been produced by grass leaves overlapping into the unplanted areas. 
(a)

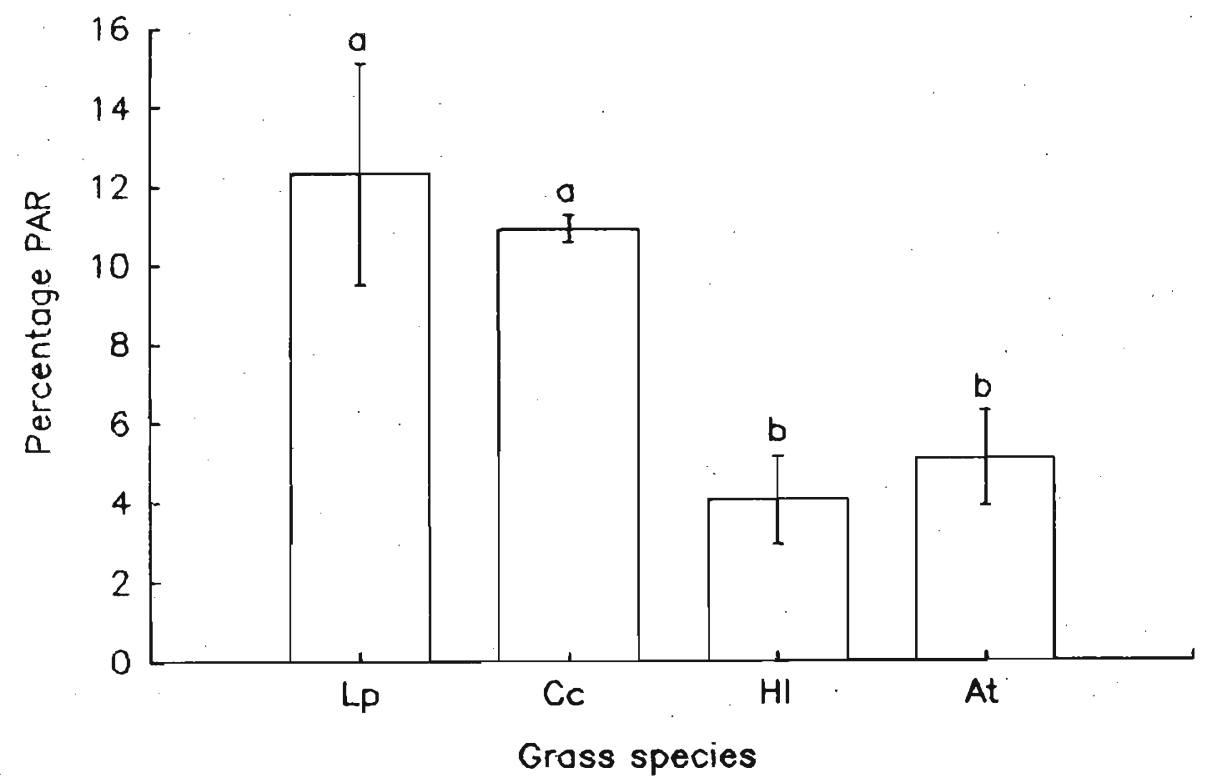

(b)

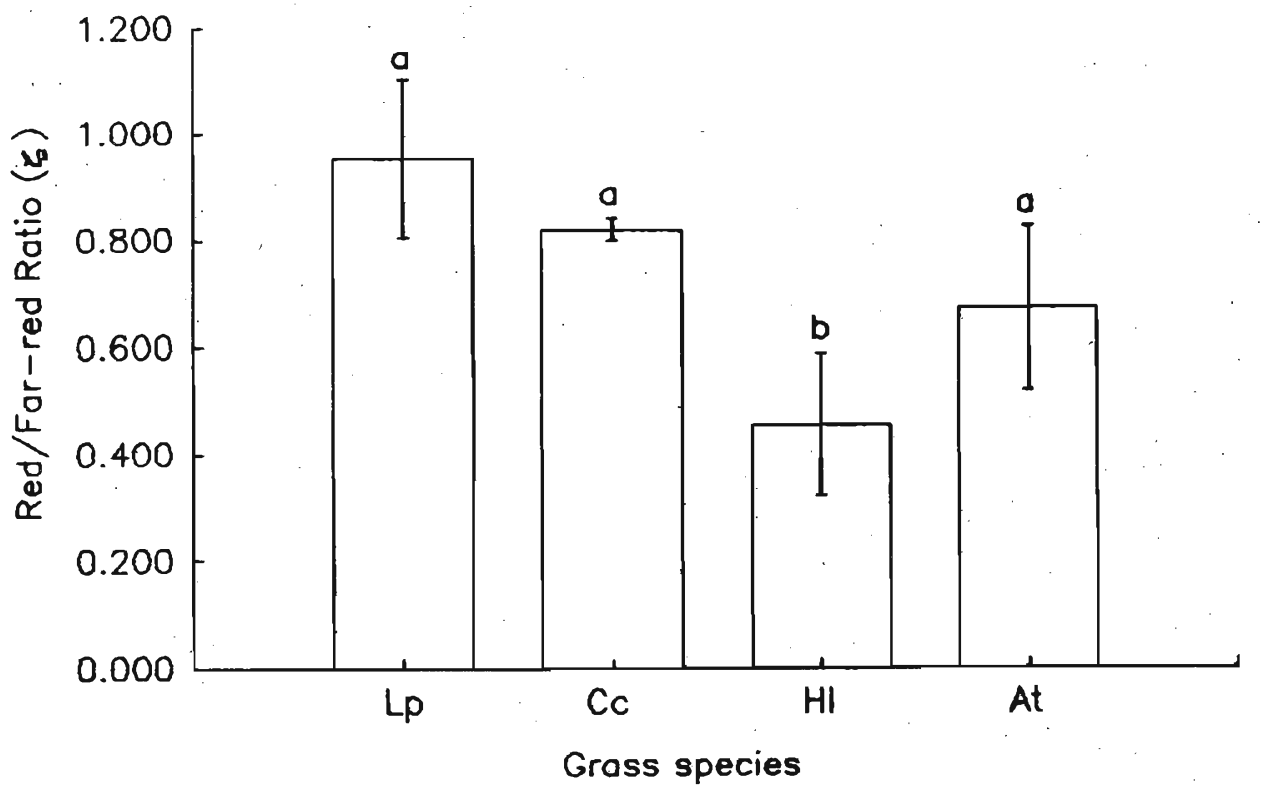

Figure 3a,b: Comparison of the quantity and quality of light within the swards of Lolium perenne (Lp), Cynosurus cristatus (Cc), Holcus lanatus (H1) and Agrostis tenuis (At). Bars sharing the same letter in each figure do not differ significantly (p<0.05). (a). Percentage PAR, (b). Red/far-red radiation ratio ( $\zeta$ ). Each value is a mean of ten replicates. 
Table 3: The effect of different heights of the swards of Lolium perenne on the growth of Trifolium repens.

Treatments (height of grass swards)

\begin{tabular}{lcccr} 
Variable & Control & $3 \mathrm{~cm}$ & $6 \mathrm{~cm}$ & $9 \mathrm{~cm}$ \\
\hline $\begin{array}{l}\text { Total number of nodes } \\
\text { Total length of }\end{array}$ & $309.0^{\mathrm{a}}$ & $149.7^{\mathrm{b}}$ & $78.0^{\mathrm{c}}$ & $40.3^{\mathrm{d}}$. \\
$\quad$ & & & & \\
$\quad$ stolons $(\mathrm{cm})$ & $363.2^{\mathrm{a}}$ & $197.9^{\mathrm{b}}$ & $104.7^{\mathrm{b}}$ & $54.8^{\mathrm{c}}$
\end{tabular}

Number of branched

$\begin{array}{lllll}\text { nodes }^{*} & 35.3^{\mathrm{a}} & 32.0^{\mathrm{a}} & 6.7^{\mathrm{b}} & 3.3^{\mathrm{b}}\end{array}$

Percentage of

\begin{tabular}{|c|c|}
\hline branched nodes $^{\dagger}$ & $12.7^{\mathrm{ab}}$ \\
\hline
\end{tabular}

Mean internode

length $(\mathrm{cm})$

$1.31^{\mathrm{a}} \quad 1.13^{\mathrm{a}} \quad 1.46^{\mathrm{a}} \quad 1.39^{\mathrm{a}}$

Mean leaf length $(\mathrm{cm})$

$0.96^{\mathrm{b}}$

$1.03^{\mathrm{ab}} \quad 1.15^{\mathrm{a}}$

Mean petiole length $(\mathrm{cm})$

$10.14^{\mathrm{ab}}$

$8.73^{\mathrm{ab}}$

$8.21^{\mathrm{a}} \quad 11.86^{\mathrm{b}}$

Each value is the mean of each parameter $(n=3)$ within each grass sward and in the comparable part of the control treatment.

* Analysis of variance was carried out on Square Root transformed data.

+ Analysis of variance was carried out on Angular transformed data.

These transformations were done to increase the homogeneity of variance.

Means were compared with Tukey's HSD value. Means sharing the same superscript within each row do not differ significantly ( $\mathrm{p}>0.05)$. 

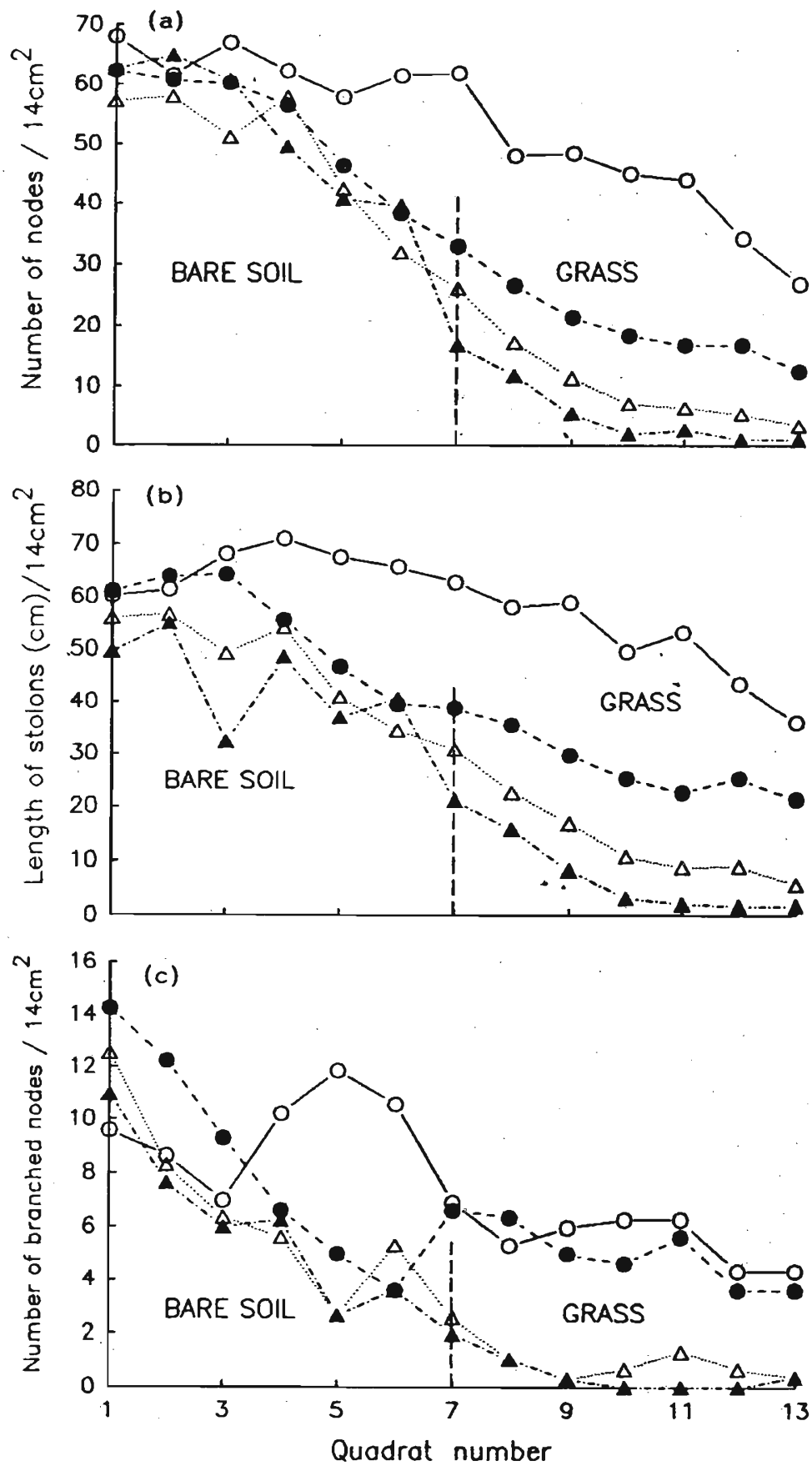

Figure 4. a-c: Comparison of stolon density of Trifolium repens, grown into bare soil (control o- - ) and into swards of Lolium perenne of $3 \mathrm{~cm}(\bullet-)$ $6 \mathrm{~cm}(\Delta \ldots . . . . . . . . . . . . \Delta)$ and $9 \mathrm{~cm}(\Delta \ldots \ldots \ldots \ldots \ldots \ldots . . . .4)$ heights. (a). Number of nodes, (b). Length of stolons, (c). Number of branched nodes. Dashed line indicates the edge of the bare soil and the grass sward (except in the control). 
Table 4: The effect of different heights of the swards of Lolium perenne on the growth of Trifolium repens.

\begin{tabular}{|c|c|c|c|c|}
\hline \multirow[b]{2}{*}{ Variable } & \multicolumn{4}{|c|}{ Treatments (height of grass swards) } \\
\hline & Control & $3 \mathrm{~cm}$ & $6 \mathrm{~cm}$ & $9 \mathrm{~cm}$ \\
\hline Number of nodes ${ }^{*}$ & $53.18^{\mathrm{a}}$ & $36.23^{b}$ & $28.95^{c}$ & $27.54^{\mathrm{d}}$ \\
\hline Length of stolons $(\mathrm{cm})$ & $58.32^{\mathrm{a}}$ & $40.75^{b}$ & $30.48^{\mathrm{e}}$ & $26.11^{\mathrm{c}}$ \\
\hline Number of branched nodes* & $7.54^{a}$ & $6.69^{\mathrm{a}}$ & $3.69^{b}$ & $3.15^{\mathrm{b}}$ \\
\hline Percentage branching ${ }^{\dagger}$ & $14.34^{\mathrm{a}}$ & $20.3^{\mathrm{a}}$ & $11.77^{\mathrm{b}}$ & $7.84^{c}$ \\
\hline
\end{tabular}

Each value is the overall mean of all quadrats of each treatment illustrated in Fig. 4.

* Analysis of variance was carried out on Square Root transformed data.

${ }^{+}$Analysis of variance was carried out with Angular transformed data in order to increase the homogeneity of variance.

Means were compared with Tukey's HSD values, and the means sharing the same superscript within each row do not differ significantly $(p>0.05)$.

\section{DISCUSSION}

As clover plants extend from bare ground into areas dominated by grasses parts of the same plant are exposed to contrasting environments. These parts behave differently and clearly respond locally to their local environment. In this respect T. repens differs from the more tightly integrated clones of e.g. Solidago canadensis studied by Hartnett and Bazzaz, ${ }^{10}$ in which parts of a clone that abut on neighbours appear to maintain their vigour by drawing on resources from other parts of the clone.

There appear to be two quite different responses made by clover shoots when they enter a grass sward - effects on the main axis and effects on lateral buds. The number of nodes (=leaves) formed on the main axis within the swards was $33 \%$ less than on comparable axes in the absence of grass, but species of grass had similar effects. However the number (and proportion) of axillary buds that broke dormancy and developed as branches was reduced by a much greater proportion and there were significant differences in branching under canopies of the different grass species. Branching was particularly reduced within swards of $H$. lanatus and A: tenuis. From the results the grass species could be arranged in a hierarchical order of aggressiveness $H$. lanatus $>A$. tenuis $>L$. perenne $>$ C. cristatus. This order agrees with that found by Turkington and Harper ${ }^{11}$ in transplant experiments (using dry weights). 
The suppression of clover growth by different grass swards could be due to the differences of different grasses. The major differences between them were in the nature of canopies, which led to the maintenance of significantly different light regimes. The leaves of $L$. perenne and $C$. cristatus are more or less similar in shape and size. The tillers tend to stand vertical and as a result the swards have a very loose and open structure, which allows more light to penetrate through. The leaves of $H$. lanatus are broader and very flexible, tending to bend horizontally; the tillers also have a creeping habit, making the sward floor very dark. It was also obvious that more dead material accumulates within the sward of $H$. lanatus, due to their shorter lifespans of leaves and tillers. ${ }^{12}$ The accumulation of dead material must contribute yet further to reduced light penetration into the sward.

The results of the defoliation experiment also support the above interpretation. Most studies of the effects of defoliation of grass-clover mixtures imitate agricultural mowing or attempt to imitate animal grazing by defoliating both species. In the present defoliation experiments only the grass was defoliated and any effects on clover have to be ascribed to the treatment of the grasses. Invasion of the grass swards was clearly inhibited by the swards and the higher the sward the greater the inhibition especially of branching. The higher the sward the less the intensity of light on the sward floor.

However, the suppression of clover growth by $H$. lanatus has also been interpreted as the result of the peculiar property of this species that it reduces the ratio of canopy transmitted red to far red radiation much more than other grasses studied . ${ }^{13,14}$ This effect of $H$. lanatus on radiation quality is confirmed in the present study.

The comparable effect of A.tenuis in suppressing branching of clover in the present experiment is more puzzling. Although the intensity of PAR was lower the quality of radiation transmitted by leaves of $A$. tenuis did not differ significantly from that transmitted by the leaves of $L$. perenne or C. cristatus. In addition to low light quantity it seemed possible that the very close knit sward of $A$. tenuis inhibited extension of clover within it. If roots develop at clover nodes the axillary bud is more likely to develop as a branch. ${ }^{15,16}$ The loosely packed grass swards (e.g. L. perenne and C. cristatus) favour rooting by $T$. repens because nodes can easily touch the soil surface, whereas in $A$. tenuis because of its high tiller density, the clover nodes may not touch the soil surface so readily and branching is less likely to occur.

Genotypic differences appear strongly in these experiments. The two clones behaved differently in different grass swards. The number of branched nodes formed by plants of Clone A was greatly reduced in swards of all four grass species but there was no significant difference between the effect of the different 
species. In contrast, branching by plants of Clone B was much more strongly reduced by $H$. lanatus and $A$. tenuis than by the other two grasses.

Except for establishment from seed all significant increases in the density of clover in a pasture must depend on branching. There may be small changes produced if the rate of formation of new nodes on an axis exceeds the rate of death of old nodes but branches are the major source of new nodes. The increase in clover content that occurs in heavily grazed or closely mown grasslands presumably depends on the rapid release of axillary buds from dormancy under these conditions. Thompson ${ }^{17}$ has shown that even under close grass canopies the bud dormancy of white clover can be broken by exposing them to red light from light emitting diodes. It seems reasonable to suppose that it is the exposure of buds to unfiltered light that accounts for at least part of the increase in clover content that follows severe defoliation of pastures. Therefore pasture management should attempt to minimize the effect of competition for light allowing efficient light utilization by grasses as well as white clover.

\section{Acknowledgement}

I thank Prof. J.L. Harper for guidance and advice and the Association of Commonwealth Universities and British Council for financial support.

\section{References}

1. Jones M. G. \& Jones L. I. (1930). The effect of varying the periods of rest in rotational grazing. Bulletin of Welsh Plant Breeding Station 11: 38-59.

2. Jones M.G. (1933). Grassland management and its influence on the sward. Empire Journal of Experimental Agriculture 1: 43-57.

3. Jones M.G. (1933). Grassland management and its influence on the sward. 11. The management of a clovery sward and its effects. Empire Journal of Experimental Agriculture 1: 122-128.

4. Jones M.G. (1933). Grassland management and its influence on the sward. 111. The management of a 'grassy' sward and its effects. Empire Journal of Experimental Agriculture 1: 224-234.

5. Jones M.G. (1933). Grassland management and its influence on the sward. $1 \mathrm{~V}$. The management of poor pastures. V. Edaphic and biotic influences on pastures. Empire Journal of Experimental Agriculture 1: 362-367.

6. Leith H. (1960). Patterns of change within grassland communities. In: The Biology of Weeds (Ed. J.L. Harper). Blackwell Scientific Publications, Oxford. pp 27-39. 
7. Solangaarachchi S.M. \& Harper J.L. (1989). The growth and asymmetry of neighbouring plants of white clover (Trifolium repens L.). Oecologia (Berlin) 78 : 208-213.

8. Trathan P. (1983). Clonal interactions of Trifolium repens and Lolium perenne. $\mathrm{PhD}$ thesis. University of Wales.

9. Woodward F.I. (1983). Instruments for the measurement of photosynthetically active radiation and red, far red and blue light. Journal of Applied Ecology. 20: 103 - 115 .

10. Hartnett D.C. \& Bazzaz F.A. (1985). The integration of neighbourhood effects by clonal genets in Solidago canadensis L.. Journal of Ecology 73: 416-429.

11. Turkington R. \& Harper J. L. (1979). The distribution and neighbour relationship of Trifolium repens in a permanent pasture. 1V. Fine-scale biotic differentiation. Journal of Applied Ecology 67: 245-254.

12. Thorhallsdottir T.E. (1983). The dynamics of a grassland community with special reference to five grasses and white clover. $\mathrm{PhD}$ thesis. University of Wales.

13. Solangaarachchi S.M. \& Harper J.L. (1987). The effect of canopy filtered light on the growth of white clover (Trifolium repens L.). Oecologia (Berlin) 72: 372-376.

14. Thompson L. \& Harper J.L. (1988). The effect of grasses on the quality of transmitted radiation and its influence on the growth of white clover (Trifolium repens). Oecologia (Berlin) $75: 343-347$.

15. Chapman D.F. (1983). Growth and demography of Trifolium repens stolons in grazed pastures. Journal of Applied Ecology 20 : 597-608.

16. Solangaarachchi S.M. (1985). The nature and control of branching pattern in white clover (Trifolium repens $\mathrm{L}$.). $\mathrm{PhD}$ thesis. University of Wales.

17. Thompson .L. (1989). The effect of radiation quality on the behaviour of grassland species. $\mathrm{PhD}$ thesis. University of Wales. 